\title{
Simultaneity Problem of Exports and Economic Growth: A Panel Data Analysis of the European Union
}

\author{
Seham H. Negem \\ Tanta University, Tanta, Egypt
}

\begin{abstract}
This paper focuses on the export-growth simultaneity problem. It attempts to investigate whether exports result in and/or from economic growth. To solve the simultaneity problem in the economic growth equation, the estimates are obtained using the simultaneous equations model; considering the direct and indirect effect through exports growth. A two-equation simultaneous equations model, SEM, of two endogenous variables, the real output, representing the economic growth, and exports growth, is developed to deal with the endogeneity problem. The appropriate tests and the estimation of the regression results are obtained using Give Win, Pc-Give. The regression analysis using panel data starts by testing for unit root for each variable included. Then the mentioned model is estimated using panel data for 28 countries as full sample and for the richest group, seven countries, of the EU. The panel data cover the period 2000-2014. For full sample and the richest group, the three-stage least squares (3SLS) technique is used to estimate the regression. The findings of this paper indicate that the effect of exports growth on economic growth does not seem to differ in the two groups. The positive feedback, bi-directional, relationship between exports growth and economic growth exists; supporting both Exports Led Growth (ELG) and Growth Led Exports (GEL) arguments in the EU economies. This finding is in line with the theoretical argument of the ability of the economic unions to benefit from the international trade. Export duties, for both full sample and the richest group, are indirectly negatively associated with economic growth. So do the tariffs of the trading partners. However, the terms of trade, indirectly and positively affected the economic growth via their direct influence on exports growth.
\end{abstract}

Keywords: SEM, ELG, GLE, EU, endogeneity problem, order and rank conditions

\section{Introduction}

In economic system, it is noted that everything is related to everything else. The simultaneity problem is then created due to the interdependence of all economic variables. One reason why several empirical studies have failed to resolve the issue of the impact of exports on economic growth is that most of them examined only part of the influence. This is because they used a single equation, ignoring the issue of simultaneity associated with exports and economic growth. Simultaneity means that one or more of the explanatory variables (right-hand side of a model equation) are jointly determined with the dependent variable (left-hand side of the same model equation); i.e. the existence of causality between the dependent and independent variables of a model, influencing each other at the same time.

Seham H. Negem, Ph.D., Dr., Faculty of Commerce, Tanta University, Tanta, Egypt.

Correspondence concerning this article should be addressed to Seham Hamed Negem, Faculty of Commerce, Tanta University, Tanta, Egypt. 
The causality issue represents an important challenge when trying to find out the influence of exports on economic growth, i.e. whether export results in and/or from economic growth. The importance of determining the causal pattern between exports and economic growth is due to the important implications for policy-makers' decisions about development strategies and the way economic growth should be targeted. Policy makers should advocate export promotion as a development strategy if exports could contribute to economic growth; however, they should advocate import substitution if economic growth causes exports growth.

Earlier empirical works regressed exports growth rates on economic growth rates to determine whether they were correlated. However, this was criticized on the ground that exports are a component of GDP, and an autocorrelation between them would be expected, and other important determinants of economic growth were excluded (Michalopoulos \& Jay, 1973; Michaely, 1977). Dollar (1991, p. 536) recognizes the possibility that causation runs in the other direction, i.e. from poor growth performance to inward-orientation. He argues that an external factor, such as a debt crisis, may cause both slow economic and exports growth.

World Bank researchers are also aware that "the link between trade strategy and macroeconomic performance is not entirely clear," and raise the question of whether an "outward-orientation leads to the better economic performance or superior economic performance paves the way for outward orientation" (World Bank, 1987, p. 83). In fact, the vast majority of the literature fails to establish the direction of causality. Theoretically, "the stage of development" theory of comparative advantage, for example, argues that economic development tends to stimulate exports as the earlier stages of development, whereas exports tend to stimulate economic development after some degree of development is attained.

To deal with the simultaneity bias problem, many methods have been proposed. One way is to carry out causality analysis to determine the direction of the relationship between exports and economic growth. Another proposed way to deal with simultaneity bias is by building a simultaneous equations model (SEM) that captures the bi-directional relationships which cause simultaneity bias in single-equation models. According to Van de Berg and Lewer (2007), SEM is the most attractive theoretical approach that accounts for the hypothesized simultaneous relationships among the model variables. Simultaneous equations models are a form of statistical model in the form of a set of linear simultaneous equations.

Trying to find out the influence of exports on economic growth, this paper contributes to the literature by applying the SEM. A simultaneous equation model, SEM, will be specified to capture the bi-directional relationships between exports and economic growth (represented by GDP per capita growth rate) to deal with this simultaneity bias in the context of the EU economies. The next section reviews some studies, which dealt with the problem of simultaneity.

Section 3 demonstrates the methodology in details for full sample and the richest countries of the European Union (panel data) for the period 2000-2014 including the specification of the simultaneous equations model. The simultaneous equations model (SEM) and tests are estimated by using GiveWin, Pc-Give, (for more details about Pc-Give see Volume I-III of Doornik and Hendary, 2003). And finally, the model results are introduced followed by concluding remarks.

\section{Exports and Economic Growth Simultaneity: Relevant Literature}

\section{Exports and Economic Growth Simultaneity: (ELG and/or GLE) Hypotheses}

International trade theory provides little guidance to the effects of international trade on economic growth. Many theoretical models, such as the comparative advantage model of Ricardo, representing the classical 
growth view, concentrated on the gains from international trade, especially static ones, but did not examine the impact on growth. Moreover, it is worth mentioning that the trade theories based on the classical ideas such as real trade theory, ignore the monetary or balance of trade payments consequences, despite the strong role such consequences play in linking exports and growth.

Important insights for understanding the relationship between trade and growth have been provided by the new growth theory, according to which trade can provide access to the advanced technological knowledge of any country's trading partners. This theory argues that trade provides access to investment and wider markets; encouraging the development process through increasing returns to innovation. The new growth theory views dynamic gains from trade as externalities that prevent the decline in the marginal product of physical capital, arguing that in this way, long-run economic growth can be enhanced by trade.

The significant positive influence of exports growth on economic growth has been shown through various channels. First, exports generate positive externality effects in the economy; especially to the import sector (see Feder, 1983 for details). Second, exports permit poor countries (small open economies) which are characterized by narrow domestic markets to benefit from economies of scale (Helpman, 1985). Third, both Balassa (1978) and Krueger (1980) add that exports enhance efficiency in resource allocation and particularly, improved capital utilization through international competitiveness. The fourth channel, through which exports affect GDP growth, was proposed by Grossman and Helpman (1991). They argued that exports facilitate the diffusion of technical knowledge, in the long run, through foreign buyers' suggestions and learning-by-doing.

Santos-Paulino (2000) discussed the main benefits to economic growth from higher exports growth which are the positive externalities resulting from greater competition in world markets and consequently greater efficiency in resource allocation, economies of scale, and technological spillovers. Moreover, Edwards (1993) discussed the effect of exports on economic growth, with reference to studies based on neoclassical production functions. At the centre of this approach is the idea that exports contribute to aggregate output in two fundamental ways: First, there is an assumption that the exports sector generates positive externalities on non exports sectors through more efficient management styles and improved production techniques. Second, it is argued that there is a productivity differential in favor of the exports sector. Consequently, an expansion of exports at the cost of other sectors will have a positive net effect on aggregate output. Thirlwall (2000) asserted that exports have powerful effects on both supply and demand within an economy and so there is a highly positive effect of exports growth on economic growth.

The reverse is considered, that there is interdependence between economic growth and exports growth. In the traditional view, exports are assumed to be exogenous to domestic output. For this reason, empirical research has examined the interdependence between economic growth and exports growth. Studies by Harrison (1996) and Dollar (1992) supported the trade effects on growth and export-led growth hypothesis. Nevertheless, Chuang (2000) states that feedback effects from economic growth to trade are also possible, as a positive relationship between productivity growth and output growth was suggested by Verdoorn's law and this consequently stimulates a comparative advantage for exports. Studies by Granger (1969) and Jung and Marshall (1985) have not supported the export-led growth hypothesis.

Jung and Marshall (1985) contend that, even if the hypothesis export-led growth is true and exports growth can cause economic growth, it is equally possible that economic growth may in turn cause exports growth. To support this view, they argue that, for example, in a case of unbalanced growth, it is highly unlikely that the domestic demand for goods from expanding industries will increase as rapidly as their production. 
Therefore, producers will be forced to seek out foreign markets to sell their commodities. In this case the causality will be from output growth to exports growth and the obvious causality between them cannot be interpreted as evidence of export-led development.

The existence of the reverse causal flow from growth to exports, which is described as the growth-led exports hypothesis, was argued with reference to developing countries by, among others, Balassa (1978) and Ram (1987) and for industrialised countries by Shan and Sun (1998) and Awokuse (2003). Some studies, with a single equation, used causality tests, taking simultaneity into consideration, and supported XLG hypothesis (Liu, Song, \& Romer 1997; Medina-Smith, 2001; Hui Lee \& Hung, 2002; Ahmed, 2004; Keong, Yuso, \& Sen 2005). Others, using the same tests of causality supported the second hypothesis of GLX (Abbas, 1998; Abu Shihab \& Abdul-Khaliq, 2014). Bi-directional relationship of exports and economic growth was detected as well (Awokuse, 2005; Mehrara \& Firouzjace, 2011). It is worth notable that the used data of most causality test studies, whether supporting XLG and/or GLX, are for case study of one country (time-series).

\section{Exports and Economic Growth: Simultaneous Equations Model}

It is important to highlight studies using simultaneous equations model to examine the relationship between exports and economic growth. Attempting to overcome most of the shortcomings of studies based on a single equation, Salvatore (1983) developed a simultaneous equations model which captures the most important quantitative aspects of the relationship between international exports and economic growth. This relationship was tested by pooling data for 52 developing nations from 1961 to 1978. His model was estimated by Full Information Maximum Likelihood (FIML), validated by dynamic simulation, and utilized to conduct dynamic policy and other counterfactual simulations. His model started from a general aggregate production function:

$$
Q=F(K, L)
$$

where $Q$ is output and $K$ and $L$ are capital and labour inputs, respectively. His constructed four system simultaneous equations model was as follows:

$$
D Y_{t}=\alpha_{0}+\alpha_{1} I_{t}+\alpha_{2} R_{t}+\alpha_{3} D X_{t}
$$

where, $D Y_{t}=$ growth of real income per capita in year $t, I_{t}=$ gross fixed capital formation as a percentage of gross domestic product (GDP), $R_{t}=$ industrial output (manufacturing plus construction) as a percentage of $G D P$, $D X_{t}=$ growth in the percentage of exports to $G D P$.

The second equation was as follows:

$$
I_{t}=b_{0}+b_{1} Y_{t}+b_{2} D Y_{t}+b_{3} X_{t}+b_{4} F_{t}
$$

where, $I_{t}=$ gross fixed capital formation as a percentage of GDP in year $t, Y_{t}=$ real income per capita in U.S. dollar, $D Y_{t}=$ growth of real income per capita, $X_{t}=$ exports as a percentage of $G D P, F_{t}=$ capital inflow (net imports of goods and services) as a percentage of GDP.

It is noted that the appearance of $D Y$ in the second equation establishes one of the simultaneity links in the model. In the first equation $D Y$ is a function of $I$ whereas, $I$ is a function of $D Y$ in the second one, moreover, there is a direct relationship between $D Y$ and $D X$ in the first equation, however an indirect relationship between $D Y$ to $X$ in the second equation. The third equation was:

$$
R_{t}=c_{0}+c_{1} D Y_{t}+c_{2} X_{t}+c_{3} R_{t-1}
$$


where, $R_{t}=$ industrial output as a percentage of $G D P ; D Y_{t}=$ the growth of domestic economy; $X_{t}=$ rate of exports; $R_{t-1}=$ rate of industrial output in the previous year.

Finally, the fourth equation was as follows:

$$
X_{t}=d_{0}+d_{1} P_{t}+d_{2} W_{t}+d_{3} R_{t}
$$

where, $X$ and $R$ are defined earlier, $P$ is the ratio of the consumer price index in the nation relative to the consumer price index of all market economies, $W$ is the index of real GDP of all market economies.

The fourth equation is linked simultaneously to the third one and the rest of the model through $R$. Salvatore (1983) found that the sign and statistical significance of estimated coefficients, also the dynamic validity simulation strongly support the model empirically. The unequivocally positive relationship between exports and economic growth was found, supporting in the conclusions of Haberler (1959) and Caves (1970) who regarded trade as an engine of growth. Salvatore (1983) concluded that trade can be very important to the development process, but is more in the nature of a handmaiden than an engine of growth.

Esfahani (1991), like Salvatore (1983), took the endogeneity of exports into consideration. A simultaneous equations model was developed to deal with the relationship between exports and economic growth with concentrating on export-promotion policy as a superior development strategy. He developed a three-equation system of $G D P$, exports, and imports growth model simultaneously. His developed model of the relationship between export performance and GDP growth rate is in some basics similar to that of Feder (1983). He assumed that $Y$, total output, is produced through two different processes. The first one is production for using domestically, $D$, and the other is production for exports, $X . K$, total capital, and $\mathrm{L}$, total labour, produced the value added in these two processes.

To capture exports externality effects Esfahani (1991) assumed that the productivity of factors used in the domestic goods production depends on the level of exports. Also, he added an intermediate good to the ingredients list for the production of each product to allow for the impact of shortages in the imported intermediate goods supply. Following Feder (1983), Esfahani (1991) used a cross-sectional data set consisting of a sample of 31 countries identified by Chenery (1980) as semi-industrialised, excluding the major oil exporters. The data were for the periods 1960-1973, 1973-1981, and 1980-1986, representing three different phases of the world economy since 1960 (Esfahani, 1991, p. 95). His paper made (according to Esfahani, 1991) two contributions. The first one is that the correlation established between exports expansion and output growth is mainly due to the contribution of exports to the reduction of import "shortages", which restrict the growth of output in many semi-industrialised countries. The second contribution of Esfahani's paper (1991) is his development of a simultaneous equations model enabling him to deal with the simultaneity problem between $G D P$ and export growth rates.

By bridging the work between the economists and sociologists on the relationship between international trade and economic growth, Sprout and Weaver (1993) provided a valuable contribution to the literature by constructing a simultaneous equations model taking into consideration the endogeneity of exports growth. The two previous groups (economists and sociologists) have contrasting opinions regarding the size and growth of the exports sector. While economists see that the larger the export sector and the greater its growth, the more the economy expands, the sociologists see an inverse relationship.

Sprout and Weaver (1993) stated the views of both economists and sociologists. The economists support international trade, free trade, and greater integration into the economy of the world for LDCs, whereas, the 
sociologists argue that foreign trade is detrimental to the interests of the LDCs. Sprout and Weaver (1993) explained the above divergence in views, by the fact that the two groups are addressing different aspects of the gains and losses from trade. The economists' tests assess the possibility of absolute gains from trade, while the sociology studies examine the relative gains (Sprout \& Weaver, 1993, p. 299). Their model consists of three simultaneous equations specified as follows:

The first equation is:

$$
D G N P=a_{1}+\left(a_{2}\right) G D I+\left(a_{3}\right) D L A B O R+\left(a_{4}\right) D X
$$

The second one is:

$$
G D I=b_{1}+\left(b_{2}\right) G D P P C+\left(b_{3}\right) D G N P P C+\left(b_{4}\right) X S H A R E+\left(b_{5}\right) K I
$$

The third equation is concerned with exports growth:

$$
D X=c_{1}+\left(c_{2}\right) D G N P+\left(c_{3}\right) P R I C E+\left(c_{4}\right) \text { TPGROWTH }+\left(c_{5}\right) \text { TPCON }+\left(c_{6}\right) \text { TSCOMP }
$$

where $D G N P=$ growth of real $G N P ; G D I=$ growth domestic investment as a percentage of GDP; DLABOR= growth of the labour force; $D X=$ growth of real exports $(D X 1)$, or growth of export share of $G D P(D X 2)$; $G D P P C=$ real $G D P$ per capita; $D G N P P C=$ growth of real GNP per capita; $X S H A R E=$ export share of GDP (exports as a percentage of $G D P$ ); $K I=$ capital inflow (net imports of goods and services) as a percentage of $G D P ; P R I C E=$ price competitiveness (inflation and exchange rate changes in the LDC relative to its five leading partners; TPGROWTH = trade partner's growth (weighted average of real GNP growth of the LDC's five leading trading partners); $T P C O N=$ trade partner concentration (proportion of total exports received by the LDC's three leading partners); TSCOMP = trade structure composite average of the value of primary exports as a percentage of total exports (PRIMX) and the value of the two leading export commodities as a percentage of total exports $(C C O N)$.

Data for 72 LDCs were used for the period from 1970 to 1984. Sprout and Weaver (1993) divided the 72 LDCs into three types, which were supported by empirical and theoretical literature, large exporters, small primary product exporters, and small non primary product exporters. The model was estimated using 2SLS.

Sprout and Weaver's results suggest that those with more processed exports benefit the most from trade (Sprout \& Weaver, 1993, p. 298), and so the small primary product exporters benefit the least. On this point, Sprout and Weaver (1993) support the sociology studies in highlighting the importance of the structure of the export sector. Sprout and Weaver (1993) concluded that the larger the exports sector, the greater is domestic investment and so they found that trade structure plays an indirect role in affecting economic growth rate as well through investment and exports growth. They found that the growth of exports sector decreases as there is an increase in the proportion of primary exports.

However, they did not find any adverse effect on the economic growth as a result of few number of trading partners. Evidence of a simultaneous relationship between economic growth and export growth among some LDCs appeared in Sprout and Weaver's paper (1993). Their test results supported the economists' and sociologists' perspectives regarding the greater gains from trade in more processed exports and in a more diversified exports sector (Sprout \& Weaver, 1993, p. 298). Sprout and Weaver's results supported the opinion of the economists regarding the size and growth of the exports sector. Finally, their findings support the argument of the sociologists that the primary export countries that fail to diverse their exports experience less economic growth from expanding the export sector than those that can diversify their exports.

To deal with the previous simultaneity problem in the openness-growth relationship, Frankel, Romer, and Cyrus (1996) used instrumental variables that are truly exogenous and are not highly correlated with trade from 
the gravity model of bilateral trade, such as proximity to trading partners. Their basic specification is given by regression equation based on Mankiw, Romer, and weil (1992). By including total trade (exports+imports) as a share of GDP, Frankel et al. (1996) extended Mankiw et al.'s empirical analysis. Mankiw et al. (1992) specified their augmented model based on the steady state of a Solow growth model with Cobb-Douglas production function and exogenous technical changes and population growth. One production function that is consistent with their empirical results is:

$$
Y=K^{1 / 3} H^{1 / 3} L^{1 / 3}
$$

In the model of Frankel et al. (1996) the dependent variable is GDP per capita at the end of the sample, 1985. At the beginning of the sample (1960), GDP per capita appears as an explanatory variable. Their basic equation is as follows:

$$
\log (Y / \text { pop })_{85}=\alpha+\beta \log (T / Y)_{i}+\gamma \log (I / Y)_{i}+\delta \log (n)_{i}+\varphi \log (S c h)_{i}+\lambda \log (Y / \text { pop })_{60}+u
$$

where, $Y$ is $G D P$; pop is the country's working-age population; $T / Y$ is total trade (exports+imports) as a share of $G D P, I / Y$ is gross investment as a share of $G D P ; n$ is the rate growth of pop; Sch is an estimate of human capital investment based on schooling.

Their sample contains 100 to 123 countries, depending on availability of some variables. Their instrumental variable regression results confirm a significant impact on GDP per capita and more specifically, the role played by openness in promoting growth is stronger in contributing to East Asian growth by both the exogenous or geographical component of openness and by the residual or policy component.

It is noted that none of the single equation studies reviewed, whether using time series or cross-sectional data, took the simultaneity issue (endogeneity problem) into consideration when investigating the relationship between exports and economic growth. Even most of the studies using causality tests are applied for a case study of one country (time-series data). The studies using simultaneous equation models focus, just, on constructing the simultaneous equations models without considering some indicators of free trade policy. Moreover, steps to form the complete simultaneous equations model have not been carried out. These steps include checking for the model identification (order and rank conditions), obtaining the reduced form from the structural form of the model, and retrieving the parameters to analyze the results. No SEM studies reviewed used 3SLS, despite its efficiency in estimating the model when over identification arises. This paper tries to consider these points when investigating the relationship between exports and economic growth for the EU economies.

\section{Methodology}

Data from 28 EU countries are pooled, full sample and the richest, for the period 2000-2014 and panel unit root tests and simultaneous equations model are employed. The data set comprises annual measures for EU 28 countries. The model is a two-equation system of economic growth and exports. The procedures of this paper can be shown as follows:

\section{The Simultaneous Equations Model}

The model specification. The purpose of this paper is to investigate the relationship between exports and economic growth with considering the simultaneity issue of this relationship. A simple model of economic growth and exports, theoretically, is expressed via two hypotheses (for more details, see, Michaely, 1977; Jung \& Marshall, 1985; Chow, 1987; Sharma, Norris, \& Cheung, 1991; Sharma \& Dhakal, 1994; Shan \& Sun, 1998; 
Hui Lee \& Huang, 2002; Parida \& Shahoo, 2007; Safdari, M. Mahmoodi, \& E. Mahmoodi, 2011).

The first hypothesis is Export led Growth (ELG) which is mathematically presented as:

$$
G D P=\alpha_{0}+\alpha_{1} X+\varepsilon_{1}
$$

where, GDP is the gross domestic product (per capita), representing the economic growth, $X$ is the growth of exports.

The second one is Growth Led Export (GLE) which is also mathematically presented as:

$$
X=\beta_{0}+\beta_{1} G D P+\varepsilon_{2}
$$

To apply the simultaneous equations model, some determinants of both economic growth and exports growth are added. The model was developed by incorporating and synthesizing partial works related to trade and economic growth. The following simultaneous equations model is developed, based on the above two equations, to capture the relationship between exports and economic growth with considering the simultaneity of this relationship.

$$
\begin{gathered}
G D P_{i t}=\alpha_{0}+\alpha_{1} E X P_{i t}+\alpha_{2} K_{i t}+\alpha_{3} L_{i t}+\alpha_{4} I M P_{i t}+\alpha_{5} S c h_{i t}+\varepsilon_{1 i t} \\
E X P_{i t}=\beta_{0}+\beta_{1} G D P_{i t}+\beta_{2} T O T_{i t}+\beta_{3} T P G D P_{i t}+\beta_{4} X d u t y_{i t}+\beta_{5} T P t a r_{i t}+\varepsilon_{2 i t}
\end{gathered}
$$

where, $G D P$ is the gross domestic product per capita growth as a measure of real total output, EXP is exports growth, $K$ is capital measured in terms of gross fixed capital formation as a proxy variable (for more details, see Sharma \& Dhakal, 1994), $L$ is labour force growth, IMP is import growth, $S c h$ is secondary school enrolment as a proxy for human capital investment based on schooling, TOT is terms of trade, TPGDP is trade partners' real GDP growth, Xduty is export duties, TPtar is trading partners' tariff rate, $t$ is the period from 2000-2014 and $i$ is for a country.

Equation (1) aims at capturing the impact of economic growth determinants and states that economic growth, represented by the growth rate of GDP (per capita), is a function of export growth as one of the main determinants of economic growth. There is a wide body of theoretical and empirical literature, based on international trade and development theories, analyzing, as stated, the strong positive links between exports and economic growth. According to Hui-Lee and Huang (2002), exports expansion is considered as the key factor promoting the economic growth. Exports growth has a stimulating influence on total factor productivity growth via its positive effect on higher rates of capital formation; the second determinants of the growth rate of GDP (per capita) of the proposed model.

Many authors, like McKinnon (1964) and Chenery and Strout (1966), discussed the effect of exports in relaxing binding foreign exchange constraints and allowing increases in imports of capital goods and intermediate goods. Herzer, Nowak-Lehmann, and Siliverstovs (2006) assert that the increase of capital goods imports in turn stimulates output growth by raising the level of capital formation. Moreover, it is suggested that these capital goods imports coming from technologically advanced countries that have knowledge and technology embodied in equipment and machinery may increase productivity and consequently economic growth. Two main variables, affecting the growth rate of GDP (per capita), are gross fixed capital formation and labor force growth. Their importance comes from their being used as indicators of the basic factors of production, which are capital and labor, respectively. It is expected for both to have positive effect. The fourth 
variable of the growth equation is imports. ILG suggests that the growth of imports can drive economic growth. Based on endogenous growth models imports can be a channel for long run economic growth since imports may provide domestic firms with foreign technology and serve as a medium for the transfer of growth enhancing R\&D knowledge (Coe, Helpman, \& Hoffmaister, 1997).

The last selected variable directly affecting GDP growth is secondary years of schooling in the total population aged 15 or over, which represents the human capital stock. This variable reflects the percentage of the skilled human power in the economy. Kebede (2002) commented that because skilled labor is mainly associated with industrial productivity, which in turn is a sign of development, it is assumed that a high stock of human capital enhances economic growth, so the human capital stock variable is expected to be positive. It is worth notable that, human capital not only works as a cause of economic growth but also grows as a result.

Equation (2) posits the determinants of the exports growth. It indicates that the growth rate of exports depends on the growth rate of GDP (per capita), Terms of trade (TOT), and the growth of GDP of the main trading partners (TPGDP) (see Appendix 1 for the main trading partners of EU). Also, among the main determinants of exports growth are export duties levied on exports (Xduty) and finally, the Tariff rate of trading partners (TPtar). Equation (2) is also intended to capture the extent to which the exports sector is governed by the internal supply factors which are the growth rate of GDP (per capita), and Xduty and external demand forces, which are TOT, TPGDP, and TPtar.

Concerning the first determinant of exports growth which is the growth rate of GDP (per capita), there is evidence based on the earlier studies (as stated in equation (1)) that export growth has a positive impact on $G D P$ growth. Here, we consider the reverse, that there is interdependence between the growth rate of GDP (per capita), and export growth. In the traditional view, exports are assumed to be exogenous to domestic output. The work of Kaldor (1993) shows, however, that this assumption could be inappropriate, as economic growth (measured by output growth) can also affect exports. Kaldor indicates the positive impact of output growth on productivity growth, and notes that improved productivity, or reduced unit costs, is expected to stimulate exports. Following this, many empirical studies on the export-output linkage have produced mixed results as to the existence of any causal relationship between export growth and output growth. According to Subasat (2002), development (an increase of growth rate of GDP per capita) stimulates export growth as development makes the economy become stronger and consequently, markets will become more efficient. Moreover, fewer bottlenecks will occur. This well-functioning economy will enable the country to penetrate into world markets through exports.

Terms of trade (TOT), as one of the most important determinants of export growth, is the ratio of an index of a country's export prices to its import prices, which at the same time are the prices of the exports of trading partners (Negem, 2008). The terms of trade are said to improve if this ratio increases so that each unit of exports pays for more imports, and to deteriorate if the ratio falls, so that each unit of exports pays for less imports. The growth of exports is determined by whether the country is capable of competing in the international market. This capability relies greatly on the price of its goods relative to those of the trading partners. As known, both domestic supply conditions and foreign demand may be reflected by the prices of world markets. If the prices of a country's goods are lower relative to the prices of other competitors, then a greater quantity of these low-priced goods will be exported. The crucial role of TOT in economic growth process comes from their role in strengthening or worsening the competitiveness of any country. Since higher values of TOT show a greater competitiveness from the trade partners, it is expected that TOT will show 
positive impact on exports growth.

Concerning the trading partners' income or GDP and its effect on export growth, it is assumed that, in the long run, trading partners' income growth largely drives movements in any country's exports by effecting changes in foreign demand. Recent studies conducted in developing countries have identified foreign demand as one of the factors that have a very strong correlation with exports (for more details see Samiei, 1994; Catao \& Falcetti, 1999). TPGDP is expected to have a positive coefficient. Contrary to the positive effect of trade partners $G D P$ on export growth, export duties (Xduty) has a negative impact on the growth of exports as it adds more expenses to the original value of exports, making them more expensive.

The trading partners' tariff rates make imported goods more expensive to domestic residents. Therefore, the demand for domestic goods will increase and demand for foreign goods will fall, which in turn will affect growth of exports. However, lowering tariffs stimulates imports (which are exports of other countries), via price reductions because lower tariff rates almost always translate into lower prices, so the quantity and value of imports is likely to rise. Also, eliminating tariffs creates dynamic economic gains through greater trade and thus a more efficient and productive economy (Slaughter, 2003). From another perspective, when high tariffs are levied, the imported goods will be more expensive and so both demand for domestic goods and production increase. Consequently, money demand will also increase, pushing domestic interest rates up.

Therefore, investors will sell foreign bonds, preferring domestic bonds, resulting in appreciation of the domestic currency. As a result of this appreciation, the value of exports to other countries will rise as the exports of trade partners who levied tariffs will be more expensive and so the growth of these exports will fall. We can conclude that levying of high tariffs by trading partners (TPtar) inversely affects both the growth of exports of a country, as a result of the fall in foreign demand and the growth of exports of trading partners, as the domestic currency will be appreciated, raising the price of exported goods. Therefore, in both cases, for the country and its trading partners, export growth will fall when high tariffs are levied by trading partners and so trading partners' tariff (TPtar) is expected to have a negative impact on export growth, which will be shown as a negative coefficient.

Then, the analytical structure of the model is that the simultaneity originates in growth of export (EXP) contributing to economic growth represented by growth rate of GDP per capita (GDP) in equation (1), whereas the Growth of Export itself is determined by economic growth in equation (2). Export growth is assumed to have positive impact on economic growth, while it is determined by various factors as indicated in equation (2). Therefore, we hypothesize that economic growth is determined directly by export growth $(E X P)$, Capital $(K)$, labour force annual growth $(L)$, import growth $(I M P)$, and human capital represented in secondary school enrolment $(S c h)$, and indirectly by various determinants of export growth, which are terms of trade (TOT), trading partners' GDP (TPGDP), export duties (Xduty), and trading partners' tariffs (TPtar). It is notable that the appearance of EXP in equation (1) and the growth rate GDP per capita establishes the simultaneity link in the model and consequently, we are not able to solve this model within a single-equation model, the approach adopted in most of the studies in the literature related to the relationship of exports and economic growth.

Some steps will be included to form the complete model. The first step is concerned with forming a reduced form from the structural form of the model then the second step involves estimating the coefficients of the reduced form. This enables achievement of the third step, which is to retrieve the structural coefficients of the model. However, before starting to estimate the model, it is important to check whether each equation of the model is identified or not, as each equation in a simultaneous equation model needs to satisfy order and rank 
conditions for identification. The reason for this is that an unidentified equation makes it impossible to retrieve its structural coefficients (see Negem, 2008 for details).

The model identification. According to Gujarati (1995), the identification problem means "whether numerical estimates of the parameters of a structural equation can be obtained from the estimated reduced form coefficients". If this can be done, it is said that the particular equation is identified. If this can not be done, then the equation under consideration is unidentified, or under identified. Econometricians use order and rank conditions to identify individual equations. The order condition, which is a necessary but not sufficient condition of identification, tells us if the equation under consideration is exactly, over, or under identified. The order condition includes checking the identifiability condition $K-k \geq m-1$, where,

$K$ is the number of exogenous or predetermined variables in the model including intercepts of the model, $k$ is the number of exogenous variables in an equation including intercept of under consideration equation, $m$ is the number of endogenous, or jointly dependent, variables in a given equation.

One of three cases might be obtained:

$K-k=m-1$, the structural equation is exactly identified.

$K-k>m-1$, the structural equation is over-identified.

$K-k<m-1$, the structural equation is under-identified.

In this system, for the first equation,

$$
\begin{aligned}
& G D P_{i t}=\alpha_{0}+\alpha_{1} E X P_{i t}+\alpha_{2} K_{i t}+\alpha_{3} L_{i t}+\alpha_{4} I M P_{i t}+\alpha_{5} S c h_{i t}+\varepsilon_{1 i t} \\
& K=10 ; \quad k=5 ; \quad m=2
\end{aligned}
$$

By applying the order condition where $K-k \geq m-1$ it is found that $10-5>2-1$ which means that this equation is over-identified.

For the second equation,

$$
\begin{aligned}
E X P_{i t} & =\beta_{0}+\beta_{1} G D P_{i t}+\beta_{2} T O T_{i t}+\beta_{3} T P G D P_{i t}+\beta_{4} \text { Xduty }_{i t}+\beta_{5} \text { TPtar }_{i t}+\varepsilon_{2 i t} \\
K & =10 ; \quad k=5 ; \quad m=2
\end{aligned}
$$

Also, by applying the order condition where $K-k \geq m-1$ it is found that $10-5>2-1$, i.e. $5>1$ which means that this equation is over-identified.

Since each of the above equations is over identified, it is possible to retrieve more than one structural coefficient from the reduced form of the equation. However, as stated, this condition is necessary but not sufficient and so the second one, which is rank condition, should be applied. The rank condition is both a necessary and sufficient condition for identification. The model is defined by the rank of the matrix which should have a dimension $(M-1)(M-1)$, where $\mathrm{M}$ is the number of endogenous variables in the model (for more details, see Negem 2008). When discussing which condition should be used, order or rank condition, Harvey (1990, p. 328) comments that the order condition is usually sufficient to ensure identifiability; however a failure to verify it will rarely result in disaster and this is not true for the rank condition. Gujarati (1995) summarized the expected results of applying order and rank conditions as follows:

if $K-k>m-1$ and the rank of the matrix is $M-1$, the equation is over-identified.

if $K-k=m-1$ and the rank of the matrix is $M-1$, the equation is exactly identified.

if $K-k \geq m-1$ and the rank of the matrix is less than $M-1$, the equation is under-identified.

if $K-k<m-1$ and the rank of the matrix is less than $M-1$, the equation is under-identified. 
$M$, as stated, is the number of endogenous variables in the model.

To obtain the rank condition involves several steps. Gujarati (2003) summarizes that the first step should be to write down the system in a tabular form. After that, we should strike out the coefficients of the row where the equation under consideration appears. The next step is to strike out the columns corresponding to those coefficients in the previous step which are nonzero. Then, the entries left in the table will give only the coefficients of the variables included in the system but not in the equation under consideration. Then all possible matrixes will be formed from these entries, like $A$, of order $M-1$ and we should obtain the corresponding determinants, which have to be unequal to zero.

Let us apply these steps to our model as follows.

As the model is:

$$
\begin{gathered}
G D P_{i t}=\alpha_{0}+\alpha_{1} E X P_{i t}+\alpha_{2} K_{i t}+\alpha_{3} L_{i t}+\alpha_{4} I M P_{i t}+\alpha_{5} S c h_{i t}+\varepsilon_{1 i t} \\
E X P_{i t}=\beta_{0}+\beta_{1} G D P_{i t}+\beta_{2} T O T_{i t}+\beta_{3} T P G D P_{i t}+\beta_{4} X d u t y_{i t}+\beta_{5} \text { TPtar }_{i t}+\varepsilon_{2 i t}
\end{gathered}
$$

so,

\begin{tabular}{llllllllllll}
\hline & Constant & $G D P_{i t}$ & $E X P_{i t}$ & $K_{i t}$ & $L_{i t}$ & $I M P_{i t}$ & $S_{c h}$ & TOT $_{i t}$ & TPGDP $_{i t}$ & Xduty $_{i t}$ & TPtar $_{i t}$ \\
\hline$G D P_{i t}$ & $-\alpha_{0}$ & 1 & $-\alpha_{1}$ & $-\alpha_{2}$ & $-\alpha_{3}$ & $-\alpha_{4}$ & $-\alpha_{5}$ & 0 & 0 & 0 & 0 \\
$E X P_{i t}$ & $-\beta_{0}$ & $-\beta_{1}$ & 1 & 0 & 0 & 0 & 0 & $-\beta_{2}$ & $-\beta_{3}$ & $-\beta_{4}$ & $-\beta_{5}$ \\
\hline
\end{tabular}

The matrix of coefficients missing from each of the above equations is:

For the $G D P_{i t}$ equation: $A_{1}=-\beta_{2} \neq 0$ or $-\beta_{3} \neq 0$ or $-\beta_{4} \neq 0$ or $-\beta_{5} \neq 0$

For the $E X P_{i t}$ equation: $A_{2}=-\alpha_{2} \neq 0$ or $-\alpha_{3} \neq 0$ or $-\alpha_{4} \neq 0$ or $-\alpha_{5} \neq 0$

Thus the rank condition allows each of the above equations to be identified, meaning that the structural coefficients can be retrieved from the reduced form coefficients.

The reduced form of the simultaneous equations model of Export and Growth. The model is specified as follows:

$$
\begin{gathered}
G D P_{i t}=\alpha_{0}+\alpha_{1} E X P_{i t}+\alpha_{2} K_{i t}+\alpha_{3} L_{i t}+\alpha_{4} I M P_{i t}+\alpha_{5} S c h_{i t}+\varepsilon_{1 i t} \\
E X P_{i t}=\beta_{0}+\beta_{1} G D P_{i t}+\beta_{2} T O T_{i t}+\beta_{3} T P G D P_{i t}+\beta_{4} X d u t y_{i t}+\beta_{5} T P t a r_{i t}+\varepsilon_{2 i t}
\end{gathered}
$$

The solution of the model can be obtained by substituting $E X P_{i t}$ in the first equation by the second one. So,

$$
\begin{gathered}
G D P_{i t}=\alpha_{0}+\alpha_{1}\left(\beta_{0}+\beta_{1} G D P_{i t}+\beta_{2} T O T_{i t}+\beta_{3} T P G D P_{i t}+\beta_{4} X_{d u t y_{i t}}+\beta_{5} \text { TPtar }_{i t}\right)+ \\
\alpha_{2} K_{i t}+\alpha_{3} L_{i t}+\alpha_{4} I M P_{i t}+\alpha_{5} S c h_{i t}+\varepsilon_{1 i t}
\end{gathered}
$$

So,

$$
G D P_{i t}=\alpha_{0}+\alpha_{1} \beta_{0}+\alpha_{1} \beta_{1} G D P_{i t}+\alpha_{1} \beta_{2} T_{O T T_{i t}}+\alpha_{1} \beta_{3} T P G D P_{i t}+\alpha_{1} \beta_{4} X d u t y_{i t}+\alpha_{1} \beta_{5} \text { TPtar }_{i t}+\alpha_{2} K_{i t}+
$$




$$
\alpha_{3} L_{i t}+\alpha_{4} I M P_{i t}+\alpha_{5} S c h_{i t}+\varepsilon_{l i t}
$$

By putting $\alpha_{1} \beta_{1} G D P_{i t}$ on the left side and changing its sign to negative.

$$
\begin{gathered}
G D P_{i t}-\alpha_{1} \beta_{1} G D P_{i t}=\alpha_{0}+\alpha_{1} \beta_{0}+\alpha_{1} \beta_{2} T O T_{i t}+\alpha_{1} \beta_{3} T P G D P_{i t}+\alpha_{1} \beta_{4} X d u t y_{i t}+\alpha_{1} \beta_{5} \text { TPtar }_{i t}+\alpha_{2} K_{i t}+\alpha_{3} L_{i t} \\
+\alpha_{4} I M P_{i t}+\alpha_{5} S c h_{i t}+\varepsilon_{l i t}
\end{gathered}
$$

By taking $G D P_{i t}$ as a common factor.

$$
\begin{gathered}
G D P_{i t}\left(1-\alpha_{1} \beta_{1}\right)=\alpha_{0}+\alpha_{1} \beta_{0}+\alpha_{1} \beta_{2} T O T_{i t}+\alpha_{1} \beta_{3} T P G D P_{i t}+\alpha_{1} \beta_{4} X_{d u t y_{i t}}+\alpha_{1} \beta_{5} \text { TPtar }_{i t}+\alpha_{2} K_{i t}+\alpha_{3} L_{i t}+ \\
\alpha_{4} I M P_{i t}+\alpha_{5} S c h_{i t}+\varepsilon_{l i t}
\end{gathered}
$$

By dividing both sides of the equation by $\left(1-\alpha_{1} \beta_{1}\right)$

$$
\begin{gathered}
G D P_{i t}=\left(\alpha_{0}+\alpha_{1} \beta_{0}\right) /\left(1-\alpha_{1} \beta_{1}\right)+\left(\alpha_{1} \beta_{2} /\left(1-\alpha_{1} \beta_{1}\right)\right) * T o T_{i t}+\left(\alpha_{1} \beta_{3} /\left(1-\alpha_{1} \beta_{1}\right)\right) * T P G D P_{i t}+\left(\alpha_{1} \beta_{4} /\left(1-\alpha_{1} \beta_{1}\right)\right) * \\
\text { Xduty }_{i t}+\left(\alpha_{1} \beta_{5} /\left(1-\alpha_{1} \beta_{1}\right)\right) * \operatorname{TPtar}_{i t}+\left(\alpha_{2} /\left(1-\alpha_{1} \beta_{1}\right)\right) * K_{i t}+\left(\alpha_{3} /\left(1-\alpha_{1} \beta_{1}\right)\right) * L_{i t}+\left(\alpha_{4} /\left(1-\alpha_{1} \beta_{1}\right)\right) * I M P_{i t}+\left(\alpha_{5} /(1-\right. \\
\left.\left.\alpha_{1} \beta_{1}\right)\right) * S^{2} h_{i t}+\left(1 /\left(1-\alpha_{1} \beta_{1}\right)\right) * \varepsilon_{l i t}
\end{gathered}
$$

So, the reduced form for $G D P_{i t}$ is:

$G D P_{i t}=\Pi_{10}+\Pi_{11} T_{o T} T_{i t}+\Pi_{12} T P G D P_{i t}+\Pi_{13} X_{d u t y}+\Pi_{14}$ TPtar $_{i t}+\Pi_{15} K_{i t}+\Pi_{16} L_{i t}+\Pi_{17} I M P_{i t}+\Pi_{18} S_{c h}+\mu_{i t}$ where,

$$
\begin{array}{ll}
\Pi_{10}=\left(\alpha_{0}+\alpha_{1} \beta_{0}\right) /\left(1-\alpha_{1} \beta_{1}\right) & \Pi_{11}=\alpha_{1} \beta_{2} /\left(\left(1-\alpha_{1} \beta_{1}\right)\right. \\
\Pi_{12}=\alpha_{1} \beta_{3} /\left(1-\alpha_{1} \beta_{1}\right) & \Pi_{13}=\alpha_{1} \beta_{4} /\left(1-\alpha_{1} \beta_{1}\right) \\
\Pi_{14}=\alpha_{1} \beta_{5} /\left(1-\alpha_{1} \beta_{1}\right) & \Pi_{15}=\alpha_{2} /\left(1-\alpha_{1} \beta_{1}\right) \\
\Pi_{16}=\alpha_{3} /\left(1-\alpha_{1} \beta_{1}\right) & \Pi_{17}=\alpha_{4} /\left(1-\alpha_{1} \beta_{1}\right) \\
\Pi_{18}=\alpha_{5} /\left(1-\alpha_{1} \beta_{1}\right) &
\end{array}
$$

To obtain the reduced form of the second equation, we begin by substituting $G D P_{i t}$ in the second equation.

$E X P_{i t}=\beta_{0}+\beta_{1}\left(\left(\alpha_{0}+\alpha_{1} \beta_{0}\right) /\left(1-\alpha_{1} \beta_{1}\right)+\left(\alpha_{1} \beta_{2} /\left(\left(1-\alpha_{1} \beta_{1}\right)\right) * T o T_{i t}+\left(\alpha_{1} \beta_{3} /\left(1-\alpha_{1} \beta_{1}\right)\right) * T P G D P_{i t}+\left(\alpha_{1} \beta_{4} /(1-\right.\right.\right.$ $\left.\left.\alpha_{1} \beta_{1}\right)\right) *$ Xduty $_{i t}+\left(\alpha_{1} \beta_{5} /\left(1-\alpha_{1} \beta_{1}\right)\right) *$ TPtar $_{i t}+\left(\alpha_{2} /\left(1-\alpha_{1} \beta_{1}\right)\right) * K_{i t}+\left(\alpha_{3} /\left(1-\alpha_{1} \beta_{1}\right)\right) * L_{i t}+\left(\alpha_{4} /\left(1-\alpha_{1} \beta_{1}\right)\right) * I M P_{i t}+$ $\left.\left(\alpha_{5} /\left(1-\alpha_{1} \beta_{1}\right)\right) * S c h_{i t}\right)+\beta_{2} T o T_{i t}+\beta_{3} T P G D P_{i t}+\beta_{4} X$ duty $_{i t}+\beta_{5}$ TPtar $_{i t}+\varepsilon_{2 i t}$

Multiplying $\beta_{1}$ in $G D P_{i t}$ equation.

$E X P_{i t}=\beta_{0}+\left(\alpha_{0} \beta_{1}+\alpha_{1} \beta_{0} \beta_{1}\right) /\left(1-\alpha_{1} \beta_{1}\right)+\left(\alpha_{1} \beta_{1} \beta_{2} /\left(1-\alpha_{1} \beta_{1}\right)\right) * T o T_{i t}+\left(\alpha_{1} \beta_{1} \beta_{3} /\left(1-\alpha_{1} \beta_{1}\right)\right) * T P G D P_{i t}+$ $\left(\alpha_{1} \beta_{1} \beta_{4} /\left(1-\alpha_{1} \beta_{1}\right)\right) * \operatorname{Xduty}_{i t}+\left(\alpha_{1} \beta_{1} \beta_{5} /\left(1-\alpha_{1} \beta_{1}\right)\right) * \operatorname{TPtar}_{i t}+\left(\alpha_{2} \beta_{1} /\left(1-\alpha_{1} \beta_{1}\right)\right) * K_{i t}+\left(\alpha_{3} \beta_{1} /\left(1-\alpha_{1} \beta_{1}\right)\right) * L_{i t}+\left(\alpha_{4} \beta_{1} /(1-\right.$ $\left.\left.\alpha_{1} \beta_{1}\right)\right) * I M P_{i t}+\left(\alpha_{5} \beta_{1} /\left(1-\alpha_{1} \beta_{1}\right)\right) * S c h_{i t}+\beta_{2} T_{0 T} T_{i t}+\beta_{3} T P G D P_{i t}+\beta_{4} X d u t y_{i t}+\beta_{5}$ TPtar $_{i t}+\varepsilon_{2 i t}$

By taking common factors and omitting similar coefficients with different signs.

So,

$E X P_{i t}=\left(\beta_{0} /\left(1-\alpha_{1} \beta_{1}\right)\right)+\left(\alpha_{0} \beta_{1}+\alpha_{1} \beta_{0} \beta_{1}\right) /\left(1-\alpha_{1} \beta_{1}\right)+\left(\beta_{2}+\left(\alpha_{1} \beta_{1} \beta_{2} /\left(1-\alpha_{1} \beta_{1}\right)\right)\right) * T o T_{i t}+\left(\beta_{3}+\left(\alpha_{1} \beta_{1} \beta_{3} /(1-\right.\right.$ $\left.\left.\left.\alpha_{1} \beta_{1}\right)\right)\right) * T P G D P_{i t}+\left(\beta_{4}+\left(\alpha_{1} \beta_{1} \beta_{4} /\left(1-\alpha_{1} \beta_{1}\right)\right)\right) * X^{2}$ duty ${ }_{i t}+\left(\beta_{5}+\left(\alpha_{1} \beta_{1} \beta_{5} /\left(1-\alpha_{1} \beta_{1}\right)\right)\right) * \operatorname{TPtar}_{i t}+\left(\alpha_{2} \beta_{1} /\left(1-\alpha_{1} \beta_{1}\right)\right) * K_{i t}$ $+\left(\alpha_{3} \beta_{1} /\left(1-\alpha_{1} \beta_{1}\right)\right) * L_{i t}+\left(\alpha_{4} \beta_{1} /\left(1-\alpha_{1} \beta_{1}\right)\right) * I M P_{i t}+\left(\alpha_{5} \beta_{1} /\left(1-\alpha_{1} \beta_{1}\right)\right) * S c h_{i t}+\varepsilon_{2 i t}$

So,

$E X P_{i t}=\left(\beta_{0}-\alpha_{1} \beta_{0} \beta_{1}+\alpha_{0} \beta_{1}+\alpha_{1} \beta_{0} \beta_{1}\right) /\left(1-\alpha_{1} \beta_{1}\right)+\left(\left(\beta_{2}-\alpha_{1} \beta_{1} \beta_{2}+\alpha_{1} \beta_{1} \beta_{2}\right) /\left(1-\alpha_{1} \beta_{1}\right)\right) * T o T_{i t}+\left(\left(\beta_{3^{-}} \alpha_{1} \beta_{1} \beta_{3}+\right.\right.$ $\left.\left.\alpha_{1} \beta_{1} \beta_{3}\right) /\left(1-\alpha_{1} \beta_{1}\right)\right) * T P G D P_{i t}+\left(\left(\beta_{4}-\alpha_{1} \beta_{1} \beta_{4}+\alpha_{1} \beta_{1} \beta_{4}\right) /\left(1-\alpha_{1} \beta_{1}\right)\right) * X d u t y_{i t}+\left(\left(\beta_{5}-\alpha_{1} \beta_{1} \beta_{5}+\alpha_{1} \beta_{1} \beta_{5}\right) /\left(1-\alpha_{1} \beta_{1}\right)\right) *$ 
$\operatorname{TPtar}_{i t}+\left(\alpha_{2} \beta_{1} /\left(1-\alpha_{1} \beta_{1}\right)\right) * K_{i t}+\left(\alpha_{3} \beta_{1} /\left(1-\alpha_{1} \beta_{1}\right)\right) * L_{i t}+\left(\alpha_{4} \beta_{1} /\left(1-\alpha_{1} \beta_{1}\right)\right) * I M P_{i t}+\left(\alpha_{5} \beta_{1} /\left(1-\alpha_{1} \beta_{1}\right)\right) * \operatorname{Sch}_{\mathrm{it}}+\varepsilon_{2 i t}$ and so,

$E X P_{i t}=\left(\beta_{0}+\alpha_{0} \beta_{1}\right) /\left(1-\alpha_{1} \beta_{1}\right)+\left(\beta_{2} /\left(1-\alpha_{1} \beta_{1}\right)\right) * T o T_{i t}+\left(\beta_{3} /\left(1-\alpha_{1} \beta_{1}\right)\right) * T P G D P_{i t}+\left(\beta_{4} /\left(1-\alpha_{1} \beta_{1}\right)\right) * X d u t y_{i t}$

$+\left(\beta_{5} /\left(1-\alpha_{1} \beta_{1}\right)\right) *$ TPtar $_{i t}+\left(\alpha_{2} \beta_{1} /\left(1-\alpha_{1} \beta_{1}\right)\right)^{*} K_{i t}+\left(\alpha_{3} \beta_{1} /\left(1-\alpha_{1} \beta_{1}\right)\right)^{*} L_{i t}+\left(\alpha_{4} \beta_{1} /\left(1-\alpha_{1} \beta_{1}\right)\right)^{*} I M P_{i t}+\left(\alpha_{5} \beta_{1} /(1-\right.$ $\left.\left.\alpha_{1} \beta_{1}\right)\right)^{*} \operatorname{Sch}_{i t}+\left(1 /\left(1-\alpha_{1} \beta_{1}\right)\right) * \varepsilon_{2 i t}$

Then the reduced form for the second equation (2) is:

$E X P_{i t}=\Pi_{20}+\Pi_{21} T_{o} T_{i t}+\Pi_{22} T P G D P_{i t}+\Pi_{23} X d u t y_{i t}+\Pi_{24}$ TPtar $_{i t}+\Pi_{25} K_{i t}+\Pi_{26} L_{i t}+\Pi_{27} I M P_{i t}+\Pi_{28} S c h_{i t}+\mu_{2 i t}$ where,

$$
\begin{array}{ll}
\Pi_{20}=\left(\beta_{0}+\alpha_{0} \beta_{1}\right) /\left(1-\alpha_{1} \beta_{1}\right) & \Pi_{21}=\beta_{2} /\left(1-\alpha_{1} \beta_{1}\right) \\
\Pi_{22}=\beta_{3} /\left(1-\alpha_{1} \beta_{1}\right) & \Pi_{23}=\beta_{4} /\left(1-\alpha_{1} \beta_{1}\right) \\
\Pi_{24}=\beta_{5} /\left(1-\alpha_{1} \beta_{1}\right) & \Pi_{25}=\alpha_{2} \beta_{1} /\left(1-\alpha_{1} \beta_{1}\right) \\
\Pi_{26}=\alpha_{3} \beta_{1} /\left(1-\alpha_{1} \beta_{1}\right) & \Pi_{27}=\alpha_{4} \beta_{1} /\left(1-\alpha_{1} \beta_{1}\right) \\
\Pi_{28}=\alpha_{5} \beta_{1} /\left(1-\alpha_{1} \beta_{1}\right) &
\end{array}
$$

The model of growth and export presented above has eight exogenous variables and its reduced form can be written as:

$$
\begin{aligned}
& G D P_{i t}=\Pi_{10}+\Pi_{11} T_{o} T_{i t}+\Pi_{12} T P G D P_{i t}+\Pi_{13} X d u t y_{i t}+\Pi_{14} \text { TPtar }_{i t}+\Pi_{15} K_{i t}+\Pi_{16} L_{i t}+\Pi_{17} I M P_{i t}+\Pi_{18} S c h_{i t}+\mu_{1 i t} \\
& E X P_{i t}=\Pi_{20}+\Pi_{21} T_{o} T_{i t}+\Pi_{22} T P G D P_{i t}+\Pi_{23} X d u t y_{i t}+\Pi_{24} \text { TPtar }_{i t}+\Pi_{25} K_{i t}+\Pi_{26} L_{i t}+\Pi_{27} I M P_{i t}+\Pi_{28} S c h_{i t}+\mu_{2 i t}
\end{aligned}
$$
where $\mu_{1 i t}$ and $\mu_{2 i t}$ are composite error terms.

\section{Unit Root Test}

Im, Pesaran, and Shin's (1998), IPS, panel unit root test technique is used to test for stationarity (determining the order of integration). The IPS test allows for heterogeneity.

In intercepts as well as in the slope coefficients. The IPS statistic is mainly an average of the individual ADF statistics computed as $t$-bar statistics. Any common time effects will be removed and the risk of correlation across countries will be reduced by regressing each variable on a set of time dummies and taking the residuals (for more details, see Negem, 2015).

\section{Data and Empirical Results}

To estimate the proposed model of exports and economic growth, the empirical work in this paper uses panel data of the EU countries. A panel of 15-year average for the period 2000-2014 is created. The full sample includes 28 European countries and their trading partners, shown in Appendix 1, both the members and non-members in the European community. The richest group of the EU 28 includes seven countries and their trading partners (for more details, see Appendix 1). The main variables of interest, as indicated, are GDP is the growth rate of gross domestic product per capita as a measure of real total output, EXP is exports growth, $K$ is capital measured in terms of gross fixed capital formation, $L$ is labour force growth, IMP is import growth, $S c h$ is secondary school enrolment as a proxy for human capital investment based on schooling, TOT is terms of trade, TPGDP is trade partners' real GDP growth, Xduty is export duties, TPtar is trading partners' tariff rate.

Exports, imports, and GDP are obtained from World Development Indicators (WDI) and International Trade Centre available at www.intracen.org/itc/market-info-tools/trade-statistics/. GDP, the growth rate of GDP per capita, which represents economic growth, for every country, was calculated using GDP divided by the population and then by using the transformation $\left(Y_{t}-Y_{t-1}\right) / Y_{t} * 100$ where $Y_{t}$ is the GDP per capita in year $t$ and 
$Y_{t-1}$ is the GDP per capita in year $t-1$. EXP and IMP, annual growth rate of exports and imports of goods and services, respectively, are calculated like GDP. Gross fixed capital formation, $K$, data were obtained from the World Development Indicators, and updated using the IMF's International Financial Statistics and Eurostat.

The explanatory variable, $L$, labour force growth rate, which is used as a proxy of Labour, employment, was calculated using International Financial Statistics-IMF elibrary and European Commission available at www.ec.europa.eu/index_en.htm. Secondary school enrolment (\% gross), Sch, representing the human capital stock, is the ratio of total secondary school enrolment to the population of the age group that corresponds to the level of education. This measure of educational attainment is the one most significantly correlated with growth. Its data are obtained using the IMF's International Financial Statistics and WDI database. Terms of trade, TOT, data were obtained from the World Development Indicators database. Trade partners' real GDP growth, $T P G D P$, is used as the average of the real GDP growth of trading partners of the EU (the importers of EU goods). The panel data were weighted average real GDP growth of the EU trading partners and obtained from the World Development Indicators database. Export duties, Xduty, data as a percentage of exports were mainly obtained from the World Development Indicators and updated using the IMF's International Financial Statistics. The explanatory variable, $T P_{t a r}$, is tariffs applied to the European Union exports by its trading partners (as an average of both members and non members trading partners) are obtained from database of Integrated Tariff European Community (TARIC), Eurostat., and World Integrated Trade Solution (WITS), as the computed weighted average of bilateral applied tariffs. In order to overcome the problems of the presence of a number of zeros in the tariff vectors, $T P_{t a r}$ are included by computing natural logarithm of $(1+$ tariff $)$.

The appropriate tests and the estimation of the Simultaneous Equations Model (SEM) results are obtained using Give Win, Pc-Give. The regression analysis using panel data starts by testing for unit root for each variable included in our regression. Then the above Simultaneous Equation model is estimated using panel data for 28 countries of the EU and for the richest group, seven countries, of the EU. The panel data cover the period 2000-2014. For full sample and the richest group, the regression was estimated using three-stage least squares (3SLS) technique. This is a general method for obtaining consistent estimates when the causing variable is endogenous. It is obvious that some explanatory variables are endogenous variables such as $S c h, K$, and $L$. The results are analyzed as follows:

\section{Unit Root Test Results}

To examine the relationship between economic growth and exports using panel data, we first test for the order of integration in the GDP, EXP, K, L, IMP, Sch, TOT, TPGDP, Xduty, and TPtar series to test whether or not unit root exists in the data. To check for the presence of a unit root for all variables, the IPS tests are conducted (both in levels and in first differences). For IPS panel unit root, individual ADF regressions, for each country in the group; full sample, and the richest, are performed for GDP, EXP, K, L, IMP, Sch, TOT, TPGDP, $X d u t y$, and TPtar, including a constant and time trend. Then a $t$-bar statistic is computed based on averaging individual ADF statistics. All variables used are expressed in real quantities by deflating them by the GDP deflator. The results of unit root test are presented in Table 1 . 
Table 1

Unit Root Results forFull Sample and the Richest Group

\begin{tabular}{lllll}
\hline \multirow{2}{*}{ Variables } & \multicolumn{3}{c}{$\begin{array}{c}\text { Full sample } \\
\text { Average ADF }\end{array}$} & $\begin{array}{c}\text { The richest* } \\
\text { Average ADF }\end{array}$ \\
\cline { 2 - 5 } & Level & First difference & Level & First difference \\
\hline EXP & $-4.536^{* *}$ & $-16.276^{* *}$ & $-2.783^{* *}$ & $-11.536^{* *}$ \\
$K$ & $-5.456^{* *}$ & $-19.875^{* *}$ & -1.356 & $-4.567^{* *}$ \\
$L$ & -2.283 & $-8.837^{* *}$ & $-3.256^{* *}$ & $-14.893^{* *}$ \\
$I M P$ & $-6.287^{* *}$ & $-25.342^{* *}$ & -1.267 & $-3.847^{* *}$ \\
Sch & -1.765 & $-4.918^{* *}$ & -1.789 & $-5.934^{* *}$ \\
TOT & $-5.387^{* *}$ & $-19.746^{* *}$ & -1.334 & $-4.967^{* *}$ \\
TPGDP & $-2.876^{* *}$ & $-9.827^{* *}$ & -1.654 & $-5.183^{* *}$ \\
Xduty & -1.987 & $-7.986^{* *}$ & $-2.537^{* *}$ & $-8.562^{* *}$ \\
TPtar & $-4.736^{* *}$ & $-18.346^{* *}$ & -1.937 & $-6.267^{* *}$ \\
\hline Notes. & -1.964 & $-7.123^{* *}$ & -2.142 & $-5.471^{* *}$ \\
\hline
\end{tabular}

Notes.

(1) GDP is the growth rate of GDP per capita, EXP is the exports growth, $K$ is capital measured in terms of gross fixed capital formation, $L$ is labour force growth, IMP is import growth, $S c h$ is secondary school enrolment, TOT is terms of trade, TPTGDP is the weighted average trading partners'GDP, Xduty is exports duty, and finally TPtar is the weighted average trading partners' tariff rate.

(2) All data are in logarithmic form.

(3) ** indicates significance at $1 \%$ level, critical value at $1 \%$ level is -2.4 (as tabulated in IPS).

(4) Under the null hypothesis of non stationarity, the test is distributed as $\mathrm{N}(0,1)$, so large negative values indicate in favour of stationarity.

On one hand, the IPS test results obtained in Table 1 on the level form of the above variables reject the null of non-stationarity, with the exception of the K, IMP, TPGDP, and TPtar in the full sample; however they do reject the null for all variables as first differenced become stationary at the $1 \%$ significance level. On the other hand, the results obtained in the same table on the level form, except for $G D P, K$, and $T P G D P$, provide evidence that all the variables for the richest group are non-stationary, i.e. they are integrated of order one I (1). This means that these variables have a stochastic trend and in this case the null hypothesis can not be rejected of the existence of unit roots for any of the variables under study with consideration of the excluded variables stated above. However, all variables are stationary, i.e. I (0) in their first difference at $1 \%$ significance.

\section{Regression Results}

The estimated coefficients of the reduced form for full sample are reported in the following table.

Table 2

The Reduced Form Estimates of the Full Sample (28 Countries)

\begin{tabular}{llll}
\hline \multicolumn{2}{l}{ The reduced form coefficient } & Estimated coefficient for the reduced form & $t$-statistics \\
\hline \multicolumn{2}{l}{ For GDP equation } & & \\
\hline$\Pi_{10}$ & (constant) & $-0.3764^{* *}$ & -2.564 \\
$\Pi_{11}$ & $($ TOT $)$ & $0.0998^{* *}$ & -3.758 \\
$\Pi_{12}$ & $($ TPGDP $)$ & $0.1834^{* *}$ & -6.372 \\
$\Pi_{13}$ & $($ Xduty $)$ & $-0.0656^{* *}$ & 2.498 \\
$\Pi_{14}$ & $($ TPtar $)$ & $-0.0097^{* *}$ & -2.371 \\
$\Pi_{15}$ & $(K)$ & $0.8137^{* *}$ & -4.294 \\
$\Pi_{16}$ & $(L)$ & $0.1764^{* *}$ & -3.219 \\
$\Pi_{17}$ & $(I M P)$ & $0.0427^{* *}$ & -2.939 \\
\hline
\end{tabular}


Table 2 continued

\begin{tabular}{|c|c|c|c|}
\hline \multicolumn{2}{|c|}{ The reduced form coefficient } & Estimated coefficient for the reduced form & $t$-statistics \\
\hline \multicolumn{2}{|c|}{$\Pi_{18}(S c h)$} & $0.0396^{* *}$ & -8.298 \\
\hline \multicolumn{2}{|c|}{$\mathrm{R}^{2}$} & 0.71 & \\
\hline \multicolumn{4}{|c|}{ For EXP equation } \\
\hline$\overline{\Pi_{20}}$ & (constant) & $0.1862 * *$ & -2.758 \\
\hline$\Pi_{21}$ & $(T O T)$ & $0.4861 * *$ & 2.623 \\
\hline$\Pi_{22}$ & $(T P G D P)$ & $0.8912 * *$ & 4.297 \\
\hline$\Pi_{23}$ & (Xduty) & $-0.3192 * *$ & -3.923 \\
\hline$\Pi_{24}$ & (TPtar) & $-0.0653 * *$ & 2.398 \\
\hline$\Pi_{25}$ & $(K)$ & $0.5871 * *$ & -6.324 \\
\hline$\Pi_{26}$ & $(L)$ & $0.1272 * *$ & -2.785 \\
\hline$\Pi_{27}$ & $(I M P)$ & $0.0308 * *$ & 2.941 \\
\hline$\Pi_{28}$ & $(S c h)$ & $0.0287 * *$ & -3.029 \\
\hline $\mathrm{R}^{2}$ & & 0.62 & \\
\hline
\end{tabular}

Note. ${ }^{* *}$ indicates significance at $1 \%$ level.

Based on the results of Table 2, for full sample, $\mathrm{R}^{2}$ for $G D P$ equation shows that $71 \%$ of the variations in the dependent variable are explained by the Regressors. $\mathrm{R}^{2}$ for EXP shows that a reasonable proportion, $62 \%$, of the variations in the dependent variable is explained by explanatory variables (Regressors). The estimated coefficients of the reduced form were retrieved to get the parameters of both equation (1) and (2) to obtain Table 3. For more details, see Appendix 2 for the process of retrieving the estimated coefficients of the reduced form.

Table 3

Retrieved Parameters for the Regression of the Full Sample

\begin{tabular}{llll}
\hline Regressors & Parameters & Equation (1) for $G D P$ & Equation (2) for $E X P$ \\
\hline Constant & $\alpha_{0}$ & -0.3066 & \\
$E X P$ & $\alpha_{1}$ & 0.2057 & \\
$K$ & $\alpha_{2}$ & 0.6929 & \\
$L$ & $\alpha_{3}$ & 0.1502 & \\
$I M P$ & $\alpha_{4}$ & 0.0364 & \\
Sch & $\alpha_{5}$ & 0.0337 & \\
Constant & $\beta_{0}$ & & -0.0675 \\
$G D P$ & $\beta_{1}$ & & 0.7215 \\
TOT & $\beta_{2}$ & & 0.4324 \\
$T P G D P$ & $\beta_{3}$ & & 0.7946 \\
$X$ duty & $\beta_{4}$ & -0.2715 \\
TPtar & $\beta_{5}$ & -0.0402 \\
\hline
\end{tabular}

The retrieved parameters obtained from the estimated reduced form coefficients presented in Table 2 are reported in Table 3. It is noted that all the variables are estimated in logarithmic form and so the analysis of the data depends on elasticities. It is a double log model for economic growth and every variable in the model separately. If $\ln G D P=\alpha_{0}+\alpha_{1} \ln E X P$ here, $\alpha_{1}$, which is $0.2057,=\frac{\Delta G D P / G D P}{\Delta E X P / E X P}$. The retrieved parameters are statistically significant, deriving from the significance of the estimated coefficients of the reduced form at the $1 \%$ level. To avoid the over identification problem when applying panel data, we use over 
identified restrictions for estimation of instrumental (exogenous) variables. Our analysis of the results depends on these retrieved parameters. The White test accepts the null hypothesis of residuals homoschedasticity. Hausman's test indicates that the fixed effect model is statistically preferable to the error-components model.

The retrieved parameters presented in column 3 for the first equation where the growth rate of GDP per capita growth $(G D P)$ is the dependent (endogenous) variable, indicate that growth of exports, EXP, gross fixed capital formation, $K$, growth of labor force, $L$, imports growth, $I M P$, and human capital represented by secondary school enrolment $(S c h)$, as predicted, have positive contributions to GDP per capita growth. Their signs are obviously positive. The gross fixed capital formation, $K$, appears to have greater effect than the other variables.

The retrieved parameters presented in column 4 for the second equation where exports growth, EXP, is the endogenous variable, all have the predicted signs. The coefficient $\beta_{1}$ implies that a one percent increase in GDP per capita growth leads to a growth of 0.72 in exports. We therefore notice that the contribution of growth of $G D P$ per capita to export growth is greater than the effect (contribution) of exports growth to GDP per capita growth, as it was indicated in the first equation that a $1 \%$ rise in exports growth simulates the GDP per capita by $0.20 \%$. The terms of trade (TOT) coefficient $\left(\beta_{2}\right)$, as expected, indicates a positive relationship with exports growth, implying that a $1 \%$ increase in TOT leads to a $0.43 \%$ growth in exports, showing a greater competitiveness of EU exports prices than trading partners' prices. The lower the price of EU exports, the greater the competitiveness of this low price relative to EU trading partners' prices, raising the EU exports growth rate.

The coefficient for trade partners' GDP growth $\left(\beta_{3}\right)$ is positively related to the growth rate of exports, as the increase in the income of trading partners causes an increase in the quantity demanded of goods and services and when these goods have lower price abroad (EU) than domestically, then the imports of these goods of trading partners (which in turn are exports of EU) increase. The positive sign of $\beta_{3}$ implies that a $1 \%$ increase of $T P G D P$ leads to an increase in the exports of EU by $0.79 \%$. As predicted, the sign of the exports duties coefficient $\left(\beta_{4}\right)$ is negative, indicating the effectiveness of adopting the free trade policy in terms of Xduty, where a cut of $1 \%$ in Xduty leads to an increase in the growth rate of exports by $0.27 \%$. Like the Xduty coefficient sign, the coefficient of trading partners' tariffs has, as expected, a negative sign, indicating the importance of implementing the economic union to reduce the international trade barriers between countries. This in turn will lead to an increase in EU exports (EU trading partners' imports) to penetrate into their markets, as a $1 \%$ cut of the tariff of trading partners of EU leads to an increase in the growth rate of EU exports by $0.04 \%$.

Table 4

The Reduced Form Estimates of the Richest Group (Seven Countries)

\begin{tabular}{|c|c|c|c|}
\hline \multicolumn{2}{|c|}{ The reduced form coefficient } & Estimated coefficient for the reduced form & $t$-statistics \\
\hline \multicolumn{4}{|c|}{ For GDP equation } \\
\hline$\overline{\Pi_{10}}$ & (constant) & $-0.0142 *$ & -1.853 \\
\hline$\Pi_{11}$ & $(T O T)$ & $0.0142 *$ & -2.158 \\
\hline$\Pi_{12}$ & $(T P G D P)$ & $0.3752 * *$ & -6.467 \\
\hline$\Pi_{13}$ & (Xduty) & $-0.0825^{*}$ & -1.724 \\
\hline$\Pi_{14}$ & (TPtar) & $-0.3144 * *$ & -3.986 \\
\hline$\Pi_{15}$ & $(K)$ & $0.2043 * *$ & -6.867 \\
\hline$\Pi_{16}$ & $(L)$ & $0.4237 * *$ & -6.035 \\
\hline$\Pi_{17}$ & $(I M P)$ & $0.2416^{*}$ & -2.015 \\
\hline$\Pi_{18}$ & $(S c h)$ & $0.2352 * *$ & -3.513 \\
\hline
\end{tabular}


Table 4 continued

\begin{tabular}{|c|c|c|c|}
\hline \multicolumn{2}{|c|}{ The reduced form coefficient } & Estimated coefficient for the reduced form & $t$-statistics \\
\hline \multicolumn{2}{|c|}{$\mathrm{R}^{2}$} & 0.67 & \\
\hline \multicolumn{4}{|c|}{ For EXP equation } \\
\hline & (constant) & $-0.0183 *$ & -2.117 \\
\hline$\Pi_{21}$ & $(T O T)$ & $0.0247^{*}$ & -1.941 \\
\hline$\Pi_{22}$ & $(T P G D P)$ & $0.6534 * *$ & -5.851 \\
\hline$\Pi_{23}$ & $($ Xduty) & $-0.1436^{*}$ & -2.002 \\
\hline$\Pi_{24}$ & (TPtar) & $-0.5475 * *$ & -3.017 \\
\hline$\Pi_{25}$ & $(K)$ & $0.1009 * *$ & -8.235 \\
\hline$\Pi_{26}$ & $(L)$ & $0.2092 * *$ & -4.975 \\
\hline$\Pi_{27}$ & $(I M P)$ & $-0.1193^{*}$ & -2.215 \\
\hline$\Pi_{28}$ & $(S c h)$ & $0.1161 * *$ & -3.764 \\
\hline $\mathrm{R}^{2}$ & & 0.61 & \\
\hline
\end{tabular}

Note. $*$ and $* *$ indicate significance at $1 \%$ and $5 \%$ levels, respectively.

Based on the results indicated in Table 4, for the richest group, $\mathrm{R}^{2}$ for GDP equation shows that $67 \%$ of the variations in the dependent variable are explained by the Regressors. $\mathrm{R}^{2}$ for EXP shows that a reasonable proportion, $61 \%$, of the variations in the dependent variable is explained by explanatory variables. The estimated coefficients of the reduced form were retrieved to get the parameters of both equation (1) and (2) to obtain Table 5. For more details, see Appendix 2 for the process of retrieving the estimated coefficients of the reduced form.

Table 5

Retrieved Parameters for the Regression of the Richest Group

\begin{tabular}{llll}
\hline Regressors & Parameters & Equation (1) for $G D P$ & Equation (2) for $E X P$ \\
\hline Constant & $\alpha_{0}$ & -0.0124 & \\
$E X P$ & $\alpha_{1}$ & 0.5749 & \\
$K$ & $\alpha_{2}$ & 0.2853 & \\
$L$ & $\alpha_{3}$ & 0.5917 & \\
$I M P$ & $\alpha_{4}$ & 0.3373 & \\
Sch & $\alpha_{5}$ & 0.3284 & \\
Constant & $\beta_{0}$ & & 0.0038 \\
GDP & $\beta_{1}$ & & 0.4938 \\
TOT & $\beta_{2}$ & & 0.0177 \\
TPGDP & $\beta_{3}$ & & 0.4674 \\
Xduty & $\beta_{4}$ & & -0.1076 \\
TPtar & $\beta_{5}$ & & -0.3916 \\
\hline
\end{tabular}

For the EU richest group, the retrieved parameters are statistically significant, deriving from the significance of the estimated coefficients of the reduced form at the $1 \%$ and $5 \%$ levels. The retrieved parameters presented in columns 3 and 4 show the same effect for all the variables of both equations (1) and (2); however, here, the greater positive influence is due to both EXP and $L$ (not to $K$ ). The results of equation two for $E X P$ growth show a positive effect of GDP per capita growth on export growth, showing, as for full sample, a bi-directional impact between GDP per capita growth and exports growth. However, the contribution of exports growth to $G D P$ per capita growth (0.5749) is close to the positive effect of GDP per capita growth to export growth (0.4938). 
Like the previous results for the full sample, TOT is positively related to export growth, implying that competition of the price in the world market positively affects growth among the EU richest group countries. As expected, $T P G D P$ has a positive coefficient, indicating that the greater the TPGDP, the greater the demand for the EU richest group countries' products. Both Xduty and TPtar, as expected, have negative coefficients. The first effect of Xduty implies the indirect negative effect on GDP per capita growth through its adverse direct effect on export growth. The second effect of TPtar implies that the EU richest group countries' exports are sensitive to changes in the tariff rates of their trading partners. The higher the TPtar is, the lower the rate of growth of exports of these countries.

\section{Concluding Remarks}

This paper addresses the simultaneity problem of the exports-economic growth relationship. It is argued that the long run growth relies upon the steady and strong expansion of its exports. Statistically significant positive relationships between international trade and growth have been found by many empirical studies, as shown when reviewing literature. To increase the number of observations and, consequently, the power of the test, a panel data approach has applied to investigate the mentioned relationship. The paper contribution to the literature is to capture the most important quantitative aspects to investigate the relationship between exports and economic growth of the EU countries by conducting a two-equation simultaneous equations model of two endogenous variables of the real output, representing the economic growth, and exports growth. Some indicators of free trade are added.

The first equation states that economic growth, represented by GDP per capita growth, is determined by exports growth, gross fixed capital formation, labour force growth, imports growth, and human capital represented by secondary school enrolment. The second equation states that exports growth is determined by GDP per capita growth, GDP growth of trading partners and indicators of free trade which are terms of trade, exports duties, and trading partners' tariff. Our model contains variables affecting GDP per capita growth either directly, as in the first equation where exports growth has direct effect on GDP per capita growth, or indirectly by affecting exports growth, as in the second equation. For instance $X$ duty negatively affects $G D P$ per capita growth indirectly through its adverse direct effect on exports growth. The model was estimated using the 3SLS method for panel data of EU for the period 2000-2014.

The results obtained, for the full sample and the richest group countries, found that there is a major direct contribution of exports expansion to GDP per capita growth. On the other hand, GDP per capita growth has a feedback positive influence on exports growth, i.e. a bi-directional positive relationship between exports growth and GDP per capita growth. Exports growth is a determinant of economic growth represented by GDP per capita growth and economic growth is a determinant of exports growth. In this regard the results of this paper also shed more light on free trade indicators affecting GDP per capita growth: Xduty, Terms of Trade and Trading Partners' tariffs. It is found that cutting Xduty raises exports growth and consequently leads to increased GDP per capita growth. The effect of Xduty on GDP per capita growth is indirect through its direct effect on exports growth, as indicated earlier. The terms of trade variable has a positive effect on exports growth as it enhances the competitiveness of EU exports. Tariffs levied by trading partners have an adverse impact on exports growth and consequently, adverse impact on GDP per capita growth. The $t$-statistics confirm the significance of the coefficients of the reduced forms of both groups, full sample and the richest, and as a consequence the significance of the retrieved parameters of the model. 
Finally, it can be concluded that by operating on the previous exogenous variables (as policy instruments) for both equations (1) and (2), the EU governments can try to increase its exports growth rate and as a consequence the economic growth. Also, it is noticed that the most important aim of any government nowadays is to adopt is the policy of increasing exports growth. This can be done by reducing Xduty to make the price of exports lower, increasing the competitiveness of EU exports and consequently increasing the growth rate of exports. To sum up, by attempting to solve the simultaneity problem in the economic growth equation of, full sample and the richest group, EU countries, the results indicate the bi-directional relationship between exports growth and economic growth, supporting both ELG and GLE hypotheses.

\section{References}

Abbas, S. (2012). Causality between exports and economic growth: Investigating suitable trade policy for Pakistan. Eurasian Journal of Business and Economics, 10(5), 91-98.

Abou Shihab, R., \& Abdul-Khaliq, S. (2014). The causal relationship between exports and economic growth in Jordan. International Journal of Business and Social Science, 5(3), 302-308.

Ahmad, M. H., Alam, S., \& Butt, M. S. (2004). Foreign direct investment, exports and domestic output in Pakistan. Islamabad, Applied Economics Research Centre, University of Karachi, 1-14.

Awokuse, T. O. (2003). Is the export-led growth hypothesis is valid for Canada? Canadian Journal of Economics, 36, $126-136$.

Awokuse, T. O. (2005). Exports, economic growth and causality in Korea. Applied Economics Letters, 12, 693-696.

Balassa, B. (1978). Export and economic growth: Further evidence. Journal of Development Economics, 5, 181-189.

CAtao, L., \& Falcetti, E. (1999). Determinants of argentina's external trade. International Monetary Fund Staff Paper, 10-11.

Caves, R. E. (1970). Export-led growth: The post-war industrial setting. In W. A. Eltis, M. F. G. Scott, and J. N. Wolff (Eds.), Induction, growth and trade: Essays in honor of sir Roy Harrod (pp. 234-254). London, Oxford University Press.

Chenery, H., \& Strout, A. (1966). Foreign assistance and economic development. American Economic Review, 56, 679-733.

Chenery, H. B. (1980). The semi-industrialised countries. Mimeo, The World Bank, Washington DC.

Chow, P. C. Y. (1987). Causality between export growth and industrial development: Empirical evidence from the NICs. Journal of Development Economics, 26(1), 55-63.

Chuang, Y. (2000). Human capital, exports and economic growth: A causality analysis for taiwan 1952-1995. Review of International Economics, 8(4), 712-720.

Coe, D. T., Helpman, E., \& Hoffmaister, A. W. (1997). North-south R\&D spillovers. Economic Journal, 107(440), $134-149$.

Dollar, D. (1991). Outward-oriented developing economies really do grow more rapidly: Evidence from 95LDCs, 1976-1985. Economic Development and Culture Change, 40(3), 523-544.

Dollar, D. (1992). Outward-oriented developing economies really do grow more rapidly: Evidence from 95LDCs, 1976-85. Econmic Development and Cultural Change, (44), 403-523.

Doornik, J. A., \& Hendry, D. F. (2003). Pc-Give Volume I-III. London, Give Win Timberlake Consultants Limited.

Edwards, S. (1993). Openness, trade liberalization, and growth in developing countries. Journal of Economic Literature, 31, $1358-1393$.

Esfahani, H. (1991). Exports, imports, and growth in semi-industrialized countries. Journal of Development Economics, 35(1) 93-116.

Feder, G. (1983). On exports and economic growth. Journal of Development Economics, 12(1/2), 59-73.

Frankel, A. J., Romer, D., \& Cyrus, T. (1996). Trade and growth in east asian countries: Cause and effect? In H. Singer, N. Hatti, and R. Tandon (Eds.). BR Publishing Corporation (India) Ltd.

Gelbach, J. B. (2005). Econ626 Lecture Notes: The Hausman Test, 1-7.

Granger, C. (1969). Investigating causal relations by econometric models and cross-spectral methods. Econometrica, 37, 424-438.

Grossman, G., \& Helpman, E. (1991). Innovation and growth in the global economy. Cambridge, MA, MIT Press.

Gujarati, D. N. (1995). Basic econometrics (3rd ed.). Singapore, Mc Graw-Hill.

Gujarati, D. N. (2003). Basic economics (4th ed.). New York, The McGraw-Hill.

Haberler, G. (1959). International trade and economic development. In J. D. Berge (Ed.), Economics of trade and development (pp. 103-112). New York: John Wiley \& Sons.

Harrison, A. (1996). Openness and growth: A time-series, cross-country analysis for developing countries. Journal of Development Economics, 48, 419-447. 
Harvey, A. (1990). The econometric analysis of time series (2nd ed). Cambridge Mass, The MIT Pess.

Helpman, E. (1985). Multinational corporations and trade structure. Review of Economic Studies, 52, 443-458.

Herzer, D., Nowak-Lehmann, D. F., \& Siliverstovs, B. (2006). Export-led growth in chile: Assessing the role of export composition in productivity growth. Developing Economies, XLIV-3 (September), 306-328.

Hui Lee, C., \& Huang, B. (2002). The relationship between exports and economic growth in east asian countries: A multivariate threshold autoregressive approach. Journal of Economic Development, 27(2), 45-68.

Im, K. S., Pesarn, M. H., \& Shin, Y. (1998). Testing for unit roots in heterogeneous panels. Dept. of Applied Economics, Cambridge University.

Jung, W. S., \& Marshall, P. J. (1985). Exports, growth and causality in developing countries. Journal of Development Economics, $18(1), 1-12$.

Kaldor, N. (1993). Capital accumulation and economic growth. In A. L. Friedrich and C. H. Douglas (Eds.), Proceedings of a Conference Held by the International Economics Association. London, Macmillan.

Kebede, E. (2002). Trade liberalisation, openness and economic growth in less-developed countries (PhD thesis). Business School, Middlesex, Middlesex University.

Keong, C. C., Yuso, P. Z., \& Sen, V. L. K. (2005). Export-led growth hypothesis in malaysia: An investigation using bounds test. Sunway Academic Journal, 2, 13-22.

Krueger, A. O. (1980). Trade policy as an input to development. American Economic Review, 70, 288-292.

Liu, X., Song, H., \& Romilly, P. (1997). An empirical investigation of the causal relationship between openness and economic growth in China. Applied Economics, 29(12), 1679-1686.

Mankiw, N. G., Romer, D., \& Weil, D. N. (1992). A contribution to the empirics of economic growth. Quarterly Journal of Economics, 107(2), 407-437.

Mckinnon, R. (1964). Foreign exchange constraint in economic development and efficient aid allocation. Economic Journal, 74, 388-409.

Medina-Smith, E. J. (2001). Is the export-led growth hypothesis is valid for developing countries? A case study of Costa Rica, New York and Geneva, United Nations, 1-51.

Mehrara, M., \& Firouzjaee, B. (2011). Granger causality relationship between export growth and GDP growth in developing countries: Panel cointegration approach. International Journal of Humanities and Social Science, 1(16), 223-231.

Michaely, M. (1977). Exports and growth: An empirical investigation. Journal of Development Economics, 4(1), 149-154.

Michalopoulos, C., \& Jay, K. (1973). Growth of exports and income in the developing world: A neoclassical view. AID Discussion Paper No. 28, Washington, DC: AID.

Negem, S. (2015). Tariffs and unemployment causality: Evidence from a panel analysis of the EU. Proceedings of Second European Academic Research Conference on Global Business, Economics, Finance and Banking. July, Zurich, Switzerland. Available at http://globalbizresearch.org/Swiss_Conference/Conference_Papers.php

Negem, S. (2008). Free trade and economic growth of egypt. PhD thesis, Hull University, England.

Parida, P. C., \& Shahoo, P. (2007). Export-led growth in south asia: A panel cointegration analysis. International Economic Journal, 21(2), 155-175.

Ram, R. (1987). Exports and economic growth in developing countries. Economic Development and Culture Change, $36,51-72$.

Safdari, M., Mahmoodi, M., \& Mahmoodi, E. (2011). The causality relationship between export and economic growth in Asian developing countries. American Journal of Scientific Research, 25, 40-45.

Salvatore, D. (1983). A simultaneous equations model of trade and development with dynamic policy simulations. Kyklos, 36(1), 66-90.

Samiei, H. (1994). Exchange rate fluctuations and UK manufacturing exports. International Monetary Fund Working Paper, 132, 9.

Santos-Paulino, A. U. (2000). Trade liberalisation and export performance in selected developing countries. Canterbury Kent, University of Kent.

Shan, J., \& Sun, F. (1998). Export-led growth hypothesis for australia: An empirical re-investigation. Applied Economics Letters, $5,423-428$.

Sharma, S. C., \& Dhakal, D. (1994). Causal analysis between exports and economic growth in developing countries. Applied Economics, 26, 1145-1157.

Sharma, S. C., Norris, M., \& Cheung, D. W. (1991). Exports and economic growth in industrialized countries. Applied Economics, 23, 697-708. 
Slaughter, M. J. (2003). Tariff elimination for industrial goods: Why the gains will far outweigh any losses. Washington, National Foreign Trade Council, INC, 1-39.

Sprout, R. V. A., \& Weaver, J. H. (1993). Exports and economic growth in simultaneous equations model. Journal of Developing Areas, 27(3), 289-309.

Subasat, T. (2002). Does export promotion increase economic growth? Some cross- section evidence. Development Policy Review, 20(3), 333-349.

Thirlwall, A. P. (2000). Trade agreements, trade liberalization and economic growth: A survey, prepared for the African development report. Oxford, UK: Blackwell Publishers.

Van De Berg, H., \& Lewer, J. J. (2007). International trade and economic growth. Google Books Result.

White, H. (1980). A heteroscedasticity-consistent covariance matrix estimator and a direct test for heteroscedasticity. Econometrica, 48, 817-838.

World Bank. (1987). World development report. Oxford University Press for the World Bank, New York.

\section{Appendix 1}

\section{EU Countries and Their Trading Partners}

\begin{tabular}{|c|c|c|c|}
\hline Ser. & Country & Exports-partners & Imports-partners \\
\hline 1 & Austria* & Germany, US, and Switzerland & Germany, Switzerland, and Italy \\
\hline 2 & Belgium* & Germany, US, and France & Netherlands, US, and France \\
\hline 3 & Bulgaria & Germany, Italy, and Turkey & Russia, Turkey, and Germany \\
\hline 4 & Croatia & Italy, Bosnia and Herzegovina, and Serbia & Italy, Russia, and China \\
\hline 5 & Cyprus & Greece, UK, and Germany & Greece, Israel, and China \\
\hline 6 & Czech Republic & Germany, Slovakia, and Poland & Germany, China, and Russia \\
\hline 7 & Denmark & Germany, US, and Norway & Germany, Norway, and China \\
\hline 8 & Estonia & Sweden, Finland, and Russia & Finland, Russia, and China \\
\hline 9 & Finland & US, Russia, and China & Russia, Sweden, and Germany \\
\hline 10 & France & Germany, Belgium, and US & Germany, Belgium, and China \\
\hline 11 & Germany* & France, US, and China & China, Russia, and Netherlands \\
\hline 12 & Greece & Turkey, Italy, and Germany & Russia, Germany, and China \\
\hline 13 & Hungary & Germany, Romania, and France & Germany, Russia, and China \\
\hline 14 & Ireland* & US, UK, and Belgium & UK, US, and China \\
\hline 15 & Italy & Germany, US, and France & China, France, and Germany \\
\hline 16 & Latvia & Russia, Lithuania, and Estonia & Russia, Lithuania, and Germany \\
\hline 17 & Lithuania & Russia, Belarus, and Estonia & Russia, Germany, and Poland \\
\hline 18 & Luxembourg* & Germany, France, and Belgium & US, China, and Belgium \\
\hline 19 & Malta & Singapore, Hong Kong, US, and Japan & Italy, Germany, and UK \\
\hline 20 & Netherlands* & Germany, Belgium, and France & China, Russia, and US \\
\hline 21 & Poland & Russia, Germany, and UK & Russia, China, and Germany \\
\hline 22 & Portugal & Spain, Angola, and US & Spain, Angola, and Germany \\
\hline 23 & Romania & Turkey, Germany, and Italy & Germany, Russia, and Italy \\
\hline 24 & Slovakia & Germany, Poland, and Hungary & Russia, South Korea, and China \\
\hline 25 & Slovenia & Austria, Russia, and Croatia & China, Germany, and Italy \\
\hline 26 & Spain & France, Germany, and Italy & Germany, France, and China \\
\hline 27 & Sweden* & Norway, US, and Germany & China, Russia, and Germany \\
\hline 28 & United Kingdom & Switzerland, Germany, and US & Germany, China, and US \\
\hline
\end{tabular}

Source: The World Factbook-CIA.

* is for the richest group based on the country's per capita income (PPP). 
Appendix 2

\section{The Process of Retrieving the Estimated Coefficients of the Reduced Form}

For simplicity, one calculated parameter is considered for the results analysis.

For the full sample

$\alpha_{1}$ can be obtained by the following:

$\alpha_{1}=\Pi_{11} / \Pi_{21}=0.1834 / 0.8912=0.2057$

$\beta_{1}$ can be obtained by the following:

$\beta_{1}=\Pi_{25} / \Pi_{15}=0.5871 / 0.8137=0.7215$

Concerning $\alpha_{2}$, it can be obtained by using

$\Pi_{15}=\alpha_{2} /\left(1-\alpha_{1} \beta_{1}\right)$ so, $0.8137=\alpha_{2} /(0.8516)$ so, $\alpha_{2}=0.6929$

Concerning $\alpha_{3}$, it can be obtained by using

$\Pi_{16}=\alpha_{3} /\left(1-\alpha_{1} \beta_{1}\right)$ so, $0.1764=\alpha_{3} /(0.8516)$ so, $\alpha_{3}=0.1502$

Concerning $\alpha_{4}$, it can be obtained by using

$\Pi_{17}=\alpha_{4} /\left(1-\alpha_{1} \beta_{1}\right)$ so, $0.0427=\alpha_{4} /(0.8516)$ so, $\alpha_{4}=0.0364$

Concerning $\alpha_{5}$, it can be obtained by using

$\Pi_{18}=\alpha_{5} /\left(1-\alpha_{1} \beta_{1}\right)$ so, $0.0396=\alpha_{5} /(0.8516)$ so, $\alpha_{5}=0.0337$

Concerning $\beta_{2}$, it can be obtained by using

$\Pi_{11}=\alpha_{1} \beta_{2} /\left(\left(1-\alpha_{1} \beta_{1}\right)\right.$ so, $0.0998=0.2057^{*} \beta_{2} / 0.8912$ so, $\beta_{2}=$ 0.4324

Concerning $\beta_{3}$, it can be obtained by using

$\Pi_{12}=\alpha_{1} \beta_{3} /\left(1-\alpha_{1} \beta_{1}\right)$ so, $0.1834=0.2057^{*} \beta_{3} / 0.8912$ so, $\beta_{3}=$

0.7946

Concerning $\beta_{4}$, it can be obtained by using

$\Pi_{13}=\alpha_{1} \beta_{4} /\left(1-\alpha_{1} \beta_{1}\right)$ so, $-0.0656=0.2057 * \beta_{4} / 0.8516$ so, $\beta_{4}=$

$-0.2715$

Concerning $\beta_{5}$, it can be obtained by using

$\Pi_{14}=\alpha_{1} \beta_{5} /\left(1-\alpha_{1} \beta_{1}\right)$ so, $-0.0097=0.2057 * \beta_{5} / 0.8516$ so, $\beta_{5}=$ $-0.0402$

Concerning $\alpha_{0}$ and $\beta_{0}$, they can be obtained by using both

following equations:

$\Pi_{10}=\left(\alpha_{0}+\alpha_{1} \beta_{0}\right) /\left(1-\alpha_{1} \beta_{1}\right) \Pi_{20}=\left(\beta_{0}+\alpha_{0} \beta_{1}\right) /\left(1-\alpha_{1} \beta_{1}\right)$

$-0.3764=\left(\alpha_{0}+0.2057 * \beta_{0}\right) /(1-0.2057 * 0.7215)$

$-0.3764=\left(\alpha_{0}+0.2057 * \beta_{0}\right) / 0.8516$

$-0.3205=\alpha_{0}+0.2057 * \beta_{0}$

$0.1862=\left(\beta_{0}+\alpha_{0} * 0.7215\right) /(1-0.2057 * 0.7215)$

$0.1586=\beta_{0}+0.7215^{*} \alpha_{0} \quad$ (2)

By putting both equations (1) and (2) together

$-0.3205=\alpha_{0}+0.2057 * \beta_{0}$

$0.1586=0.7215^{*} \alpha_{0}+\beta_{0}$

By multiplying equation (2) by -0.2057 and adding to equation

(1)

$-0.3205=\alpha_{0}+0.2057 * \beta_{0}$

$-0.0326=-0.1484 * \alpha_{0}-0.2057 * \beta_{0}$

$-0.3521=1.1484 \alpha_{0} \alpha_{0}=-0.3066$

By replacing the value of $\alpha_{0}$ in equation (1) we can get the value

For the richest group

$\alpha_{1}$ can be obtained by the following:

$\alpha_{1}=\Pi_{11} / \Pi_{21}=0.0142 / 0.0247=0.5749$

$\beta_{1}$ can be obtained by the following:

$\beta_{1}=\Pi_{25} / \Pi_{15}=0.1009 / 0.2043=0.4938$

Concerning $\alpha_{2}$, it can be obtained by using

$\Pi_{15}=\alpha_{2} /\left(1-\alpha_{1} \beta_{1}\right)$ so, $0.2043=\alpha_{2} / 0.7161$ so, $\alpha_{2}=0.2853$

Concerning $\alpha_{3}$, it can be obtained by using

$\Pi_{16}=\alpha_{3} /\left(1-\alpha_{1} \beta_{1}\right)$ so, $0.4237=\alpha_{3} / 0.7161$ so, $\alpha_{3}=0.5917$

Concerning $\alpha_{4}$, it can be obtained by using

$\Pi_{17}=\alpha_{4} /\left(1-\alpha_{1} \beta_{1}\right)$ so, $0.2416=\alpha_{4} / 0.7161$ so, $\alpha_{4}=0.3373$

Concerning $\alpha_{5}$, it can be obtained by using

$\Pi_{18}=\alpha_{5} /\left(1-\alpha_{1} \beta_{1}\right)$ so, $0.2352=\alpha_{5} / 0.7161$ so, $\alpha_{5}=0.3284$

Concerning $\beta_{2}$, it can be obtained by using

$\Pi_{11}=\alpha_{1} \beta_{2} /\left(\left(1-\alpha_{1} \beta_{1}\right)\right.$ so, $0.0142=0.5749 * \beta_{2} / 0.7161$ so, $\beta_{2}=$

0.0177

Concerning $\beta_{3}$, it can be obtained by using

$\Pi_{12}=\alpha_{1} \beta_{3} /\left(1-\alpha_{1} \beta_{1}\right)$ so, $0.3752=0.5749^{*} \beta_{3} / 0.7161$ so, $\beta_{3}=$ 0.4674

Concerning $\beta_{4}$, it can be obtained by using

$\Pi_{13}=\alpha_{1} \beta_{4} /\left(1-\alpha_{1} \beta_{1}\right)$ so, $-0.0825=0.5749 * \beta_{4} / 0.7161$ so, $\beta_{4}=$ $-0.1076$

Concerning $\beta_{5}$, it can be obtained by using

$\Pi_{14}=\alpha_{1} \beta_{5} /\left(1-\alpha_{1} \beta_{1}\right)$ so, $-0.3144=0.5749 * \beta_{5} / 0.7161$ so, $\beta_{5}=$ $-0.3916$

Concerning $\alpha_{0}$ and $\beta_{0}$, they can be obtained by using both following equations:

$\Pi_{10}=\left(\alpha_{0}+\alpha_{1} \beta_{0}\right) /\left(1-\alpha_{1} \beta_{1}\right) \Pi_{20}=\left(\beta_{0}+\alpha_{0} \beta_{1}\right) /\left(1-\alpha_{1} \beta_{1}\right)$

$-0.0142=\left(\alpha_{0}+0.5749 \beta_{0}\right) / 0.7161$

$-0.0102=\alpha_{0}+0.5749 \beta_{0} \quad$ (1)

$-0.0183=\left(\beta_{0}+\alpha_{0} * 0.4938\right) / 0.7161$

$-0.0131=\beta_{0}+0.4938 \alpha_{0} \quad(2)$

By multiplying equation (2) by -0.5749 and adding to equation (1)

$-0.0095=0.7612 \alpha_{0}$ so, $\alpha_{0}=-0.0124$

By replacing the value of $\alpha_{0}$ in equation (1) we can get the value of $\beta_{0}$

$0.0022=0.5749 \beta_{0}$ so, $\beta_{0}=0.0038$

of $\beta_{0}$

$-0.3205=\alpha_{0}+0.2057 * \beta_{0}$

$-0.3205=-0.3066+0.2057^{*} \beta_{0}$

$-0.3205+0.3066=0.2057 * \beta_{0} \beta_{0}=-0.0675$ 


\section{Appendix 3}

\section{Hausman and White Tests Results}

Hausman's specification test:

The purpose of the Hausman test is to test for model mis-specification where the null hypothesis, $\mathrm{H}_{0}$ : the model is correctly specified against the alternative that the model is mis-specified, is tested (see Gelbach, 2005 for details). In the model procedure, Hausman's specification test is used to compare two stage-least square (2SLS) with three stage-least square (3SLS), used to estimate the simultaneous equations model of this paper, for a class of estimators for which 3SLS is asymptotically efficient. Hausman's test is used to determine whether to use fixed or random effects models when applying panel analysis. Hausman's test is used as a kind of Wald $x^{2}$ test with $k-1$ freedom degrees where $k$ is the number of regressors.

White's test:

White's test, a test for heteroscedasticity, is a test used in statistics as well as econometrics to establish whether the residual variance of a variable in a regression model is constant, i.e. homoscedasticity exists (see White, 1980 for more details). This constant variance can be tested by regressing the squared residuals from a regression model onto the regressors, the cross-products of the regressors and the squared regressors, then inspecting $\mathrm{R}^{2}$. A GARCH model is used if homoscedasticity is rejected. There is one way to correct for heteroscedasticity is to compute the weighted least squares estimator using a hypothesised specification (one of the regressors or its square) for the variance (Negem, 2008).

The Results of Hausman's and White's Tests for Our Model

\begin{tabular}{lllll}
\hline \multirow{2}{*}{ Tests } & \multicolumn{3}{c}{ Full sample } & The richest group \\
\cline { 2 - 5 } & GDPequ. & EXPequ. & GDPequ. & EXPequ. \\
\hline Hausman test & 1.73 & 1.56 & 1.49 & 1.52 \\
White test & 20.7 & 16.4 & 17.3 & 13.9 \\
\hline
\end{tabular}

Note. Hausman test is the Hausman $F$-statistic to test for model misspecification. 